\title{
DITERMINAN EKSTERNAL DAN PERILAKU SEKS PRA NIKAH REMAJA SMA
}

\author{
External Determinant With Sexual Behavior On Premarital Teenagers \\ Of Senior High School \\ Winarni ${ }^{1}$ Suparmi $^{2}$ \\ Dosen STIKES ‘Aisyiyah Surakarta \\ bunda.aya06@gmail.com
}

\begin{abstract}
ABSTRAK
Latar belakang, Lingkungan dimana seseorang tinggal dan melakukan interaksi dalam kehidupan merupakan salah satu factor yang berpengaruh terhadap perilaku seseorang. Perilaku remaja dipengaruhi antara lain media, linkungan rumah, dan lingkungan sekolah. Pada remaja terjadi perubahan fisik, mental, dan psikososial secara cepat dan berdampak pada berbagai aspek kehidupan. Aspek tersebut antara lain pergeseran sikap yang permisif hubungan dengan lawan jenis. Sikap tersebut akan mempengaruhi perilaku seksual remaja. Hasil survei KPAI menunjukkan bahwa 93,7\% siswa SMP dan SMA pernah melakukan ciuman, 21,2\% remaja SMP mengaku pernah aborsi, dan 97\% remaja SMP dan SMA pernah menonton film porno.

Tujuan dalam penelitian ini adalah untuk menganalisis determinan eksternal dengan perilaku seksual pranikah pada remaja SMA di Kota Surakarta.

Metode penelitian Jenis penelitian observasional analitik pendekatan waktu cross sectional. Populasi 1663 siswa dan siswi 3 SMA di Surakarta. Sampel diambil 113 dengan proporsional random sampling. Analisis menggunakan uji $X^{2}$, untuk membuktikan Hubungan variabel bebas (teman sebaya, peran orang tua, tempat tinggal, pendapatan orang tua) dengan variabel terikat (perilaku seksual pranikah) $\mathrm{H}_{\mathrm{o}}$ ditolak bila bila $p$ value $<0,05$. Analisis multivariat menggunakan regresi logistik untuk melihat vareabel mana yang paling berpengaruh.

Hasil penelitian, Nilai $\mathrm{R}^{2}$ sebesar 0,451 yang bearti variabel teman sebaya, pengawasan orangtua, tempat tinggal, dan pendapatan orang tua, memberikan pengaruh terhadap perilaku seks pra nikah remaja SMA sebesar $45,1 \%$, sedangkan $54,9 \%$ dipengaruh variabel lain diluar model penelitian.
\end{abstract}

Kata Kunci: Determinan Eksternal, Perilaku Seksual, Remaja

\section{ABSTRACT}

Background: The person's behavior is influenced by several factor, one of them is the environmental factor where a person lives and interacts with others in the daily. Similarly, the teenager's behaviour is influenced several factors such as media, family environment, and school environment. On teenagers, they get the physical, mental, and psychosocial changes quickly, affecting various aspects in a life, one of them is the transition of permissive behavior in the relation to the 
opposite sex. This case can influence the sexual behavior on teenagers. The KPAI survey shows that 93,7\% of junior high school and senior high school students have done a kiss, 21,2 \% of junior high school teenagers admit for having an abortion, and 97\% of junior high school and senior high school students have watched the pornographic films.

The aim: This research is aimed to analyze the external determinant with the premarital sexual behavior on the teenagers of senior high school in Surakarta. Method: The type of this research is observational analytics with the cross sectional approach. The population is 1663 boys and 3 girls as the students of senior high school in Surakarta. This research takes 113 samples with proporsional random sampling. The data analysis applies $X^{2}$ test, to know the relation of independent variable (peers, parent's role, living place, parent's income) with the dependent variable (the premarital sexual behavior) $H_{o}$ is ignored if $p$ value $<0,05$. The multivariat analysis uses the logistic's regression to know which one of the most influential variable.

Result: The $R^{2}$ score is about 0,451, it means the variable of peers, parent's protect, living place, and parent's income give the influence towards premarital sexual behavior on teenagers of senior high school about 45,1\%, while 54,9\% is influenced by other variables beyond the research design.

Keywords: External Determinant, Sexual Behavior, Teenagers

\section{PENDAHULUAN}

Masa remaja disebut juga masa peralihan, pada masa ini terjadi perubahan fisik, mental, dan psikososial yang cepat,yang berdampak pada berbagai aspek kehidupan, salah satunya pergeseran sikap yang permisif pada hubungan dengan lawan jenis (Zulhaini dan Nasution, 2011).

Perilaku seks di kalangan remaja saat ini sangat mengkhawatirkan, sehingga berdampak pada persoalan KTD, aborsi dan kejadian HIV dan AIDS semakin tahun semakin meningkat. Remaja selalu ingin berusaha mencari lebih banyak lagi informasi mengenai seks, oleh karena itu remaja mencari berbagai sumber informasi yang dapat diperoleh melalui media-media seperti televisi, koran, radio dan internet, boleh jadi mendorong remaja melakukan hubungan seks pranikah (Suwarni, 2013; Sari, 2014).

Malhotra (2013) melaporkan bahwa sekitar 40\% remaja usia 15-19 tahun dan sebesar 75\% remaja usia 20-24 tahun telah melakukan seksual pranikah. Setiap tahun terjadi sekitar 9 juta kasus penyakit menular seksual (IMS)terjadi pada usia 15-24 tahun. Remaja usia 15-19 yang terkena kasus HIV sebanyak 2,036 kasus, sedangkan sebanyak 6,327 kasus HIV terjadi pada 20-24 tahun (Richards, 2013). Hasil survei KPAI menunjukkan bahwa 93,7\% siswa SMP dan SMA pernah melakukan ciuman, 21,2\% remaja SMP mengaku pernah aborsi, dan 97\% remaja SMP dan SMA pernah menonton film porno (Yulianto, 2014). Di Kota Surakarta remaja SMU sebagian besar pernah melakukan ciuman bibir $10,53 \%$, melakukan ciuman dalam 5,6\%, melakukan onani atau masturbasi $4,23 \%$, dan melakukan hubungan seksual sebanyak3,09\% (Darmasih et al, 2011). 
Dampak perilaku seksual pranikah yang nyata secara fisik adalah terjadinya kehamilan tidak diinginkan dan aborsi pada remaja. Hasil penelitian ditemukan seratus orang hamil dari dua ratus remaja putri pelaku seks pranikah (50\% dari sampel), dan sembilan puluh dari seratus remaja hamil itu melakukan aborsi (90\%). Dampak dari hubungan seks pranikah yang berkaitan dengan harga diri ditandai oleh perasaan ragu terhadap dirinya, tidak percaya diri, dirinya merasa bersalah, kotor, rasa takut tidak diterima, serta penghinaan terhadap masyarakat (Susanto, 2013; Sari, 2014).

Penyebab remaja terjerumus pada seks bebas salah satunya kepribadian yang lemah. Ciri kepribadian lemah antara lain daya tahan terhadap tekanan dan tegangan rendah, harga diri yang rendah, kurang bisa mengekspresikan diri, kurang menghargai hak dan kewajiban orang lain, kurang bisa mengendalikan emosi serta tidak dapat mengatasi masalah dan konflik dengan baik.Remaja harus bisa menilai konsekuensi yang diyakini sebagai hasil perilaku tertentu, misalnya perilaku seksual pranikah (Hidayat, 2013; Alwisol, 2014; Hadiyanti, 2013).

Berdasarkan hasil survey yang dilakukan pada beberapa sekolah SMA di Surakarta, pada jam pulang sekolah diketahui bahwa banyak siswa SMA laki-laki dan perempuan berboncengan $(70 \%)$ dengan tangan remaja putri berpegangan pada remaja pria $(55 \%)$, ini merupakan salah satu bentuk seksual pranikah yaitu berpegangan. Oleh karena itu penulis tertarik melakukan penelitian tentang "Seberapa besar pengaruh Determinan Eksternal terhadap Perilaku Seksual Pranikah Pada Remaja SMA di Kota Surakarta”. Tujuan dalam penelitian ini adalah untuk. Menganalisis determinan eksternal dengan perilaku seksual pranikah pada remaja SMA di Kota Surakarta.

\section{METODE PENELITIAN}

Jenis penelitian ini adalah penelitian observasional analitik yang bertujuan untuk mengungkapkan hubungan korelatif antar variabel Dengan metode pendekatan waktu cross sectional yaitu penelitian yang menekankan waktu pengukuran/observasi data variabel independen dan dependen hanya satu kali pada satu saat.

Populasi dalam penelitian ini adalah siswa dan siswi dari 3 SMA yang beraada di Surakarta, berjumlah 1663 siswa.Dalam penelitian ini pengambilan sampel sebesar 113 yang di dapat dari hasil perhitungan dengan rumus $\mathrm{N}=\mathrm{f}$ $\left(\alpha, \beta, \mathrm{VB}, \mathrm{R}^{2}\right)$ (Dahlan, 2013).

Teknik sampling yang digunakan adalah proporsional random sampling. Untuk memperoleh sampel di atas, dilakukan secara acak sederhana yaitu dengan mengundi anggota populasi atau teknik undian. Besarnya diperoleh menggunakan formula yang lebih sederhana yaitu :

$$
\mathrm{n}=\frac{\mathrm{F}}{\mathrm{N}} \times n
$$

Dalam penelitian ini terdapat dua variabel yang diteliti yaitu: Variabel bebas: Determinal eksternal yang meliputi teman sebaya, peran orang tua, tempat tinggal, pendapatan orang tua. Variabel terikat: Perilaku sek pranikah remaja SMA 
Instrumen penelitian yang digunakan dalam penelitian ini berupa kuesioner. Pertanyaan yang digunakan ialah pertanyaan tertutup (closed ended) dengan bentuk pertanyaan Dichotommous choice. Teknik Pengumpulan Data menggunakan data primer yaitu yang data yang diperoleh langsung dari responden melalui kuesioner.

Analisis univariat mendeskripsikan karakteristik setiap variabel penelitian. Pada umunnya dalam analisis ini hanya menghasilkan distribusi frekuensi dan presentase dari tiap variabel. Mendeskripsikan variabel bebas determinan eksternal yang meliputi teman sebaya, peran orang tua, tempat tinggal, pendapatan orang tua dan Variabel terikat perilaku seksual pranikah.

Analisis bivariat Analisis yang dilakukan untuk melihat hubungan antara variabel bebas dengan variabel terikat (Notoatmodjo, 2015). Analisis menggunakan uji $X^{2}$, analisis ini digunakan untuk membuktikan signifikansi Hubungan variabel bebas (teman sebaya, peran orang tua, tempat tinggal, pendapatan orang tua) dengan variabel terikat (perilaku seksual pranikah) $\mathrm{H}_{\mathrm{o}}$ diterima bila $p$ value $\geq 0,05 ; \mathrm{H}_{\mathrm{o}}$ ditolak bila bila $p$ value $<0,05$.

Analisis multivariat Analisis yang dilakukan untuk melihat hubungan antara variabel bebas dengan variabel terikat secara bersama sama untuk melihat vareabel mana yang paling berpengaruh dengan menggunakan regresi logistik.

\section{HASIL DAN PEMBAHASAN}

\section{Analisis Univariat}

Data statistik deskriptif teman sebaya dapat dilihat pada tabel.1. sebagai berikut :

Tabel 1: Statistik Deskriptif Teman Sebaya

\begin{tabular}{cccc}
\hline Vareabel & Hasil Pengukuran & $\mathrm{n}$ & $\%$ \\
\hline Teman Sebaya & Tinggi & 50 & $44,25 \%$ \\
& Rendah & 63 & $55,75 \%$ \\
Pengawasan Orangtua & Total & 113 & $100 \%$ \\
& Tinggi & 66 & $58,41 \%$ \\
& Rendah & 47 & $41,59 \%$ \\
Tempat Tinggal & Total & 113 & $100 \%$ \\
& Tinggi & 16 & $14,16 \%$ \\
& Rendah & 97 & $85,84 \%$ \\
Pendapatan Orang Tua & Total & 113 & $100 \%$ \\
& Tinggi & 55 & $48,67 \%$ \\
& Rendah & 58 & $51,33 \%$ \\
& Total & 113 & $100 \%$ \\
\hline
\end{tabular}

Sumber : Data Primer

Data statistik deskriptif perilaku seksual pra nikah remaja dapat dilihat pada tabel 2. sebagai berikut :

Tabel 2: Statistik Deskriptif Perilaku Seksual

\begin{tabular}{ccccccccccccc}
\hline \multirow{2}{*}{ JK } & \multicolumn{2}{c}{ Berpelukan } & \multicolumn{2}{c}{ Berciuman } & \multicolumn{2}{c}{ Meraba } & \multicolumn{2}{c}{ Petting } & \multicolumn{2}{c}{ Oral Seks } & \multicolumn{2}{c}{ Intercourse } \\
\cline { 2 - 12 } & Ya & Tidak & Ya & Tidak & Ya & Tidak & Ya & Tidak & Ya & Tdk & Ya & Tidak \\
$\mathrm{P}$ & 23 & 42 & 32 & 23 & 18 & 47 & 1 & 64 & 0 & 65 & 0 & 65 \\
$\mathrm{~L}$ & 16 & 21 & 29 & 9 & 22 & 16 & 4 & 34 & 2 & 36 & 2 & 36 \\
\hline \multicolumn{3}{l}{ Sumber : Data Primer }
\end{tabular}


Perilaku seks pranikah merupakan tingkah laku yang berhubungan dengan dorongan seksual dengan lawan jenis maupun sesama jenis yang dilakukan sebelum adanya pernikahan (Kustanti, 2013). Perilaku seks di kalangan remaja saat ini sangat mengkhawatirkan, terbukti dari hasil penelitian pada Tabel 2. menunjukkan remaja SMA telah melakukan petting 5 respoden $(4,85 \%)$, oral sek 2 responden $(1,94 \%)$, intercourse 2 reponden $(1,29 \%)$ dari 103.

Menurut Sarwono (2013) dalam upaya mengisi peran sosial, seorang remaja mendapatkan motivasinya dari meningkatnya libido, energi seksual (limbido) berkaitan dengan kematangan fisik remaja. Kurang pengetahuan kesehatan reproduksi pada remaja yang sudah berkembang kematangan seksual, kurang mendapat pengarahan dari orang tua, yang berkaitan dengan akibat perilaku seks pranikah maka mereka sulit mengendalikan rangsangan yang membuat mereka melakukan perilaku seksual secara bebas tanpa mengetahui resiko yang terjadi. Gejala ini banyak terjadi di kota-kota besar, banyak kebebasan pergaulan antar jenis kelamin .

Penyebaran media informasi dan rangsangan seksual melalui media massa yang berkaitan dengan teknologi yang canggih seperti, internet, majalah, televisi, video. Remaja cenderung ingin tahu dan ingin mencoba serta ingin meniru apa yang dilihat dan didengarnya. Ketidaktahuan orang tua maupun sikap yang masih menabukan pembicaraan seks dengan anak bahkan cenderung membuat jarak dengan anak, berdampak pada pengetahuan remaja tentang seksualitas sangat kurang. Peran orang tua sangatlah penting, terutama pemberian pengetahuan tentang seksualitas. Semakin tinggi tingkat pemantauan orang tua terhadap anak, semakin rendah kemungkinan perilaku menyimpang menimpa remaja.

\section{Analisis Bivariat}

a. Hubungan teman sebaya dengan perilaku seksual pranikah.

Tabel 3. Hubungan Teman Sebaya dengan Perilaku Seksual Pranikah

\begin{tabular}{ccccccc}
\hline Teman Sebaya & \multicolumn{2}{c}{ Melakukan } & \multicolumn{2}{c}{ Tdk Melakukan } & \multicolumn{2}{c}{ Jumlah } \\
& $\mathrm{n}$ & $\%$ & $\mathrm{n}$ & $\%$ & $\mathrm{n}$ & $\%$ \\
\hline Tinggi & 28 & $56,0 \%$ & 22 & $44,0 \%$ & 50 & $100 \%$ \\
Rendah & 55 & $87,3 \%$ & 8 & $12,7 \%$ & 63 & $100 \%$ \\
Total & 83 & $73,5 \%$ & 30 & $26,5 \%$ & 113 & $100 \%$ \\
\hline
\end{tabular}

Sumber : Data Primer

Kategori teman sebaya berdasarkan nilai rata-rata sebesar 32,20. Aktivitas teman sebaya tinggi jika $X>32,20$. Aktivitas teman sebaya rendah jika $X<32,20$.

Tabel 3. menunjukkan aktivitas teman sebaya tinggi dan melakukan perilaku seksual sebesar $28(56,0 \%)$, lebih besar dibandingkan yang tidak melakukan perilaku seksual $22(44,0 \%)$. Sedangkan aktivitas teman sebaya rendah dan melakukan perilaku seksual sebesar 55 (87,3\%), lebih besar dibandingkan yang tidak melakukan perilaku seksual $8(12,7 \%)$. 
Hasil penelitian menunjukkan bahwa ada hubungan teman sebaya dengan perilaku seks pranikah $X^{2}$ hitung $(14,006)>X_{\text {tabel }}^{2}(3,841)$ dan $P$ $<0,001<0,05$ disimpulkan ada hubungan signifikan antara aktivitas teman sebaya orangtua remaja SMA dengan perilaku seks pra nikah. OR = 0,185 atau OR $<1$ artinya remaja SMA yang aktivitasnya teman sebanya tinggi menurunkan risiko melakukan perilaku seks pra nikah. Berarti bahwa semakin baik dukungan teman sebaya maka akan semakin mengurangi perilaku seks pranikah. Pernyataan ini didukung oleh penelitian terdahulu dari Morris, Young dan Jones (2013), bahwa kelompok teman sebaya mempengaruhi perilaku seksual remaja.

Hal ini sesuai dengan Crocket, et al (2013) yang menyatakan teman sebaya dianggap untuk mengerahkan utama di bidang sosial angkutan pada perilaku seksual remaja. Pengaruh teman sebaya dapat terjadi pada beberapa tingkatan. Teman sebaya adalah sumber utama informasi tentang seks, dimana mana seks dapat terjadi. Pernyataan ini didukung oleh Malholtra (2012), Teman sebaya merupakan salah satu sumber informasi tentang seks yang cukup signifikan dalam membentuk pengetahuan, sikap dan perilaku seksual remaja.

Pengaruh teman sebaya sangatlah menentukan perilaku-perilaku yang sering ditunjukan remaja dalam keseharian mereka bergaul dengan teman-temannya. Bentuk-bentuk penyimpangan perilaku seks pranikah yang tampak dalam aktivitas kehidupan remaja yang dapat kita lihat selama ini adalah aktivitas-aktivitas yang berhubungan dengan kedekatan remaja dengan lawan jenisnya. Dalam usia remaja, mengenal lawan jenis lebih dekat sudah umum terjadi dan sering kita kenal dengan istilah penjajakan atau pacaran, dalam pacaran biasanya remaja selalu berusaha menyisihkan waktu mereka untuk bisa bersama dengan pasangannya untuk saling bertukar pikiran, berbagi cerita, saling mencurahkan perhatian dan kasih sayang.

Hasil penelitian ini mendukung penelitian Hidayat (2013), hasil penelitian menunjukkan bahwa jenis kelamin, sikap terhadap seksualitas, pengaruh dari teman sebaya dan paparan media pornografi memiliki hubungan yang signifikan dengan perilaku seksual remaja. Hasil penelirtian yang senada yaitu dari penelitian Suwarni (2013), menunjukkan bahwa Ada hubungan antara perilaku seksual teman sebaya dengan perilaku seksual remaja.

b. Hubungan pengawasan orang tua dengan perilaku seks pranikah.

Tabel 4. Hubungan Pengawasan Orang Tua dengan Perilaku Seksual Pranikah

\begin{tabular}{ccccccc}
\hline Orang Tua & \multicolumn{2}{c}{ Melakukan } & \multicolumn{2}{c}{ Tdk Melakukan } & \multicolumn{2}{c}{ Jumlah } \\
& $\mathrm{n}$ & $\%$ & $\mathrm{n}$ & $\%$ & $\mathrm{n}$ & $\%$ \\
\hline Tinggi & 40 & $60,6 \%$ & 26 & $39,4 \%$ & 66 & $100 \%$ \\
Rendah & 43 & $91,5 \%$ & 4 & $8,5 \%$ & 47 & $100 \%$ \\
Total & 83 & $73,5 \%$ & 30 & $26,5 \%$ & 113 & $100 \%$ \\
\hline \multicolumn{2}{l}{ Sumber : Data Primer, 2016}
\end{tabular}


Katageori peranan orangtua berdasarkan nilai rata-rata yaitu sebesar 34,87. Peranan orangtua tinggi atau baik jika $\mathrm{X}>34,87$. Peranan orangtua rendah atau kurang baik jika $X<34,87$.

Tabel 4. menunjukkan aktivitas teman sebaya tinggi dan melakukan perilaku seksual sebesar 28 (56,0\%), lebih besar dibandingkan yang tidak melakukan perilaku seksual 22 (44,0\%). Sedangkan aktivitas teman sebaya rendah dan melakukan perilaku seksual sebesar $55(87,3 \%)$, lebih besar dibandingkan yang tidak melakukan perilaku seksual $8(12,7 \%)$

Hasil penelitian menunjukkan bahwa ada hubungan orangtua dengan perilaku seks pranikah dimana $X^{2}$ hitung $(13,427)>X^{2}$ tabel ( 3,841) dan $P<0,001<0,05$ disimpulkan ada hubungan signifikan antara oang tua dengan perilaku seks pra nikah. $\mathrm{OR}=0,143$ atau OR $<1$ artinya remaja yang orangtuanya mempunyai peranan tinggi atau baik menurunkan risiko melakukan perilaku seks pra nikah. Berarti bahwa semakin baik pengawasan orangtua maka semakin mengurangi perilaku seksual pranikah pada siswa. Pernyataan ini didukung oleh penelitian terdahulu dari Richards (2013), bahwa remaja yang tumbuh dalam keluarga atau orangtua yang peduli dan berkomunikasi tentang seks dengan mereka akan menjadikan remaja tersebut terlibat dalam perilaku seksual yang aman. Orangtua memiliki kemampuan untuk mempengaruhi keputusan seksual anak-anak mereka. Komunikasi orangtua-anak tentang seks dan hubungan orangtua-anak merupakan faktor penting dalam pembentukan sikap dan perilaku seksual yang aman (Wayomi, at all, 2011).

Hal ini didukung oleh Suwarni (2013), hasil penelitiannya menunjukkkan bahwa ada hubungan antara monitoring parental dengan perilaku seksual remaja. Ahmadi et al (2013) juga menyatakan bahwa pengawasan orangtua dan afiliasi dengan rekan-rekan berhubungan dengan perilaku seksual remaja yang menyimpang.

Komunikasi orang tua dengan anak memegang peranan penting dalam membina hubungan keduanya. Orang tua yang kurang bisa berkomunikasi dengan anaknya akan menimbulkan konflik hubungan sehingga dapat berdampak pada perilaku seksual remaja. Pengawasan orangtua dapat didefinisikan sebagai pengetahuan orangtua terhadap kegiatan anak-anak mereka dan apa yang mereka lakukan. Hal ini sama saja dengan bentuk perlindungan orang tua terhadap berbagai risiko perilaku remaja, seperti penggunaan zat berbahaya atau perilaku seksual, dimana pengawasan tersebut bervariasi sesuai dengan umur, jenis kelamin atau etnis dan itu umumnya menurun dengan usia (Tome, 2012).

Hidayat (2013) menyatakan bahwa Pengawasan dari orang tua yang kurang akan mempercepat remaja melakukan hubungan seksual. Pengawasan orang tua merupakan faktor penting yang mempengaruhi perilaku seksual remaja. Remaja yang diawasi orang tuanya akan menunda bahkan menghindari hubungan seksual sedangkan pada 
remaja tanpa pengawasan orang tua akan melakukan hubungan seksual pertama pada usia lebih dini.

c. Hubungan tempat tinggal dengan perilaku seks pranikah. Tabel 5. Hubungan Tempat tinggal dengan Perilaku Seksual Pranikah

\begin{tabular}{ccccccc}
\hline Tempat Tinggal & \multicolumn{2}{c}{ Melakukan } & \multicolumn{2}{c}{ Tdk Melakukan } & \multicolumn{2}{c}{ Jumlah } \\
& $\mathrm{n}$ & $\%$ & $\mathrm{n}$ & $\%$ & $\mathrm{n}$ & $\%$ \\
\hline Kos & 15 & $93,8 \%$ & 1 & $6,2 \%$ & 16 & $100 \%$ \\
Orang tua/saudara & 68 & $70,1 \%$ & 29 & $29,9 \%$ & 97 & $100 \%$ \\
Total & 83 & $73,5 \%$ & 30 & $26,5 \%$ & 113 & $100 \%$ \\
\hline
\end{tabular}

Sumber : Data Primer

Tabel 5. menunjukkan tempat tinggal bersama orang tua/ saudara dan melakukan perilaku seksual sebesar 68 (70,1\%), lebih besar dibandingkan yang tidak melakukan perilaku seksual 29 (29,9\%). Sedangkan remaja yg tinggal di kos dan melakukan perilaku seksual sebesar $15(93,8 \%)$, lebih besar dibandingkan yang tidak melakukan perilaku seksual $1(6,2 \%)$

Hasil penelitian menunjukkan bahwa ada hubungan antara tempat tinggal dengan perila ku seks pranikah dimana $X^{2}$ hitung $(3,938)>$ $X^{2}$ tabel $(3,841)$ dan $P \quad 0,047<0,05$ disimpulkan ada hubungan signifikan antara tempat tinggal dengan perilaku seks pra nikah. OR = 6,397 artinya remaja SMA yang kos berpeluang melakukan seks pra nikah 6,397 kali lebih besar dibandingkan dengan remaja yang ikut orangtua atau saudara.

Hubungan seks pranikah umumnya berawal dari masa awal pacaran. Pada masa pacaran ini hubungan intim dilakukan kalangan remaja. Baik pelajar, mahasiswa, pemuda-pemudi tidak sekolah, mereka yang tinggal di kos atau di desa. Waktu pacaran tergiur melakukan cumbu rayu, peluk cium dan bila gejolak nafsu tidak terkendali berlanjutnya hubungan badan. Saat pacaran, pemuda mulai mengarahkan rayuan berhubungan seks dengan coba-coba, mulai dari raba-raba, cium, pelukan hingga hubungan badan. Tempatnya bias di bioskop yang gelap di tengah pemutaran film di tempat rekreasi, tempat kost, di rumah ketika orang tua tidak lagi ada, bahkan sengaja menginap di hotel (Tanjung, 2014).

Jarak dari rumah ke sekolah yang jauh membuat remaja terkadang memang memilih kost agar proses belajarnya tidak terganggu, tetapi tinggal di kost membuat lemahnya pengawasan orang tua dalam membangun komunikasi dengan anak, orang tua hanya berpikiran bagaimana mengirimkan uang kepada anaknya. Hal ini membuat anak kost rentan dengan perilaku seks bebas karena mereka memiliki kebebasan penuh dalam mengatur hidupnya tanpa adanya larangan dan pengawasan dari orang tua, sehingga bebas bergaul dengan siapa saja dan di lingkungan manapun termasuk lingkungan negatif yang lambat laun akan mempengaruhi perilaku mereka menjadi negatif pula. Pada umumnya perilaku negatif anak kost dipengaruhi oleh tidak adanya 
pengawasan dari orang tua, lingkungan pergaulan yang negatif dan kebebasan hidup di tempat kost (Adeoye, at al, 2013).

d. Hubungan pendapatan orang tua dengan perilaku seks pranikah.

Tabel 6. Hubungan Pendapatan Orang Tua dengan Perilaku Seksual

\begin{tabular}{ccccccc} 
Pranikah & \multicolumn{10}{l}{ Jumlah } \\
\hline Pendapatan Orang & \multicolumn{2}{c}{ Melakukan } & \multicolumn{2}{c}{ Tdk Melakukan } & \multicolumn{2}{c}{ Jum } \\
Tua & $\mathrm{n}$ & $\%$ & $\mathrm{n}$ & $\%$ & $\mathrm{n}$ & $\%$ \\
\hline Diatas rata-rata & 50 & $90,9 \%$ & 5 & $9,1 \%$ & 66 & $100 \%$ \\
Dibawah rata-rata & 33 & $56,9 \%$ & 25 & $43,1 \%$ & 47 & $100 \%$ \\
Total & 83 & $73,5 \%$ & 30 & $26,5 \%$ & 113 & $100 \%$ \\
\hline
\end{tabular}

Sumber : Data Primer, 2016

Katageori pendapatkan berdasarkan nilai rata-rata yaitu sebesar Rp. 2.901.770. Pendapatan di atas rata-rata jikan pendapatan $>\mathrm{Rp}$. 2.901.770. Pendapatan di bawah rata-rata jikan pendapatan< Rp. 2.901 .770

Tabel 6. menunjukkan pendapatan orangtua diatas rata rata dan melakukan perilaku seksual sebesar 50 (90,9\%), lebih besar dibandingkan yang tidak melakukan perilaku seksual $5(9,1 \%)$. Sedangkan pendapatan orangtua dibawah rata rata dan melakukan perilaku seksual sebesar $33(56,9 \%)$, lebih besar dibandingkan yang tidak melakukan perilaku seksual $25(43,1 \%)$.

Hasil penelitian menunjukkan bahwa ada hubungan antar pendapatan orangtua dengan perilaku seks pranikah dimana $X^{2}$ hitung ( 16,747$)>X^{2}$ tabel $(3,841)$ dan $P(<0,001)<0,05$ disimpulkan ada hubungan signifikan antara pendapatan orangtua dengan perilaku seks pra nikah. OR $=7,576$ artinya remaja SMA yang yang orang tauanya mempunyai pendapatan lebih besar berpeluang melakukan seks pra nikah 6,397 kali lebih besar dibandingkan dengan remaja yang pendatan orang tuanya dibawah UMR. Berarti bahwa semakin besar pendapatan orang tua maka semakin meningkatkan perilaku seksual pranikah pada siswa. Pernyataan ini didukung oleh Sarwono (2013) bahwa, faktor yang mempengaruhi perilaku seksual remaja menunjuk kepada faktor-faktor sosial ekonomi seperti rendahnya pendapatan dan taraf pendidikan, besarnya jumlah keluarga dan rendahnya nilai agama yang bersangkutan.

Keadaan ekonomi keluarga erat hubungannya dengan belajar anak. Anak yang sedang belajar selain harus terpenuhi kebutuhan pokoknya, misalnya makan, minum, pakaian, perlindungan kesehatan, juga membutuhkan fasilitas belajar seperti ruang belajar, meja, kursi, penerangan, alat tulis menulis, buku dan lain-lain. Fasilitas belajar itu hanya dapat terpenuhi jika orang tua mempunyai cukup uang. Jika anak hidup dalam keluarga yang miskin, kebutuhan pokok anak kurang terpenuhi sehingga belajar anak terganggu. Akibat yang lain anak selalu dirundung kesedihan 
sehingga anak merasa minder dengan temannya, hal ini juga pasti akan mengganggu belajar anak (Suryosaputro et al, 2014).

\section{Analisis Multivariat}

a. Regresi Logistik

Uji hipotesis dalam penelitian ini menggunakan regresi linier berganda digunakan untuk mengetahui hubungan harga diri, efikasi diri, dan pengendalian diri dengan perilaku seks pra nikah. Perhitungan menggunakan program SPSS. Hasil persamaan regresi linier berganda adalah sebagai berikut :

Tabel 7. Regresi Logistik

Sumber: data primer

\begin{tabular}{llcccc}
\hline & & & \multicolumn{3}{c}{ Confidence Interval 95\% } \\
\multicolumn{1}{c}{ Vareabel } & $\beta$ & $\operatorname{Exp}(\beta)$ & $\mathrm{p}$ & Lower & Upper \\
\hline Teman Sebaya & $-1,125$ & 0,325 & 0,040 &, 111 &, 950 \\
Pengawasan OT & $-1,898$ & 0,150 & 0,003 &, 042 &, 531 \\
Tempat Tinggal & 2,197 & 8,996 & 0,056 &, 947 & 85,511 \\
Pendapatan OT & 1,992 & 7,332 & 0,001 & 2,277 & 23,611 \\
\hline
\end{tabular}

$\beta_{1}=-1,125$ variabel teman sebaya dengan parameter negatif $(-1,125)$ artinya remaja SMA yang aktivits teman sebanya tinggi menurunkan risiko melakukan perilaku seks pra nikah.

$\beta_{1}=-1,898$ variabel peranan orangtua dengan parameter negatif (1,898) artinya remaja SMA yang peranan orangtuanya tinggi menurunkan risiko melakukan perilaku seks pra nikah.

$\beta_{1}=2,197$ variabel tempat tinggal dengan parameter positif $(2,197)$ artinya remaja SMA yang kos meningkat risiko melakukan perilaku seks pra nikah.

$B_{2}=1,992$ variabel pendapatan dengan parameter positif $(1,992)$ artinya remaja SMA yang penapatan orangtuanya tinggi meningkat risiko melakukan perilaku seks pra nikah.

Exp (B) variabel teman sebaya sebesar 0,325 artinya remaja yang aktivitas teman sebaya tinggi menurunkan risiko melakukan perilaku seks pra nikah.

Exp (B) variabel peranan orangtua sebesar 0,150 artinya remaja yang orangtuanya mempunyai peranan tinggi atau baik menurunkan risiko melakukan perilaku seks pra nikah.

Exp (B) variabel tempat tinggal sebesar 8,996 artinya remaja SMA yang kos berpeluang melakukan seks pra nikah 8,996 kali lebih besar dibandingkan dengan remaja yang ikut orangtua atau saudara.

Exp (B) variabel pendapatan sebesar 7,332 artinya remaja SMA yang pendapatan orangtua tinggi berpeluang melakukan seks pra nikah 7,332 kali lebih besar dibandingkan dengan remaja yang pendapatan orangtuanya rendah.

Hasil persamaan regresi linier berganda adalah sebagai berikut : Remaja SMA yang aktivits teman sebanya tinggi menurunkan risiko melakukan perilaku seks pra nikah, peranan orangtuanya tinggi menurunkan risiko melakukan perilaku seks pra nikah, remaja SMA 
yang kos meningkat risiko atau berpeluang melakukan seks pra nikah 8,996 kali lebih besar dibandingkan dengan remaja yang ikut orangtua atau saudara, sedangkan pendapatan orangtuanya tinggi berpeluang melakukan seks pra nikah 7,332 kali lebih besar dibandingkan dengan remaja yang pendapatan orangtuanya rendah.

Dari hasil analisis didapatkan nilai $\mathrm{R}^{2}$ sebesar 0,451 atau 45,1\% menunjukkan gabungan variabel teman sebaya, pengawasan orangtua, tempat tinggal, dan pendapatan orang tua, memberikan sumbangan pengaruh terhadap perilaku seks pra nikah remaja SMA sebesar 45,1\% (yang dijelaskan oleh model regresi logistik) sedangkan sisanya $54,9 \%$ dipengaruh variabel lain diluar model penelitian (variabel luar yang tidak diteliti)

\section{SIMPULAN DAN SARAN}

\section{Simpulan}

Ada hubungan dari variabel teman sebaya dengan perilaku seksual pranikah dimana, hasil koefisien regresi teman sebaya bernilai negatif yang berarti remaja SMA yang aktivits teman sebanya tinggi menurunkan risiko melakukan perilaku seks pra nikah. Ada hubungan orangtua dengan perilaku seksual pranikah dimana, hasil koefisien regresi orangtua bernilai negatif yang berarti bahwa pengawasan orangtuanya baik menurunkan risiko melakukan perilaku seks pra nikah. Ada hubungan tempat tinggal dengan perilaku seksual pranikah, dimana hasil koefisien regresi tempat tinggal bernilai positif yang berarti bahwa remaja SMA yang kos meningkat risiko melakukan perilaku seks pra nikah 8,996 kali lebih besar dibandingkan dengan remaja yang ikut orangtua atau saudara. Ada hubungan pendapatan orangtua dengan perilaku seksual pranikah, hasil koefisien regresi orangtua bernilai positif yang berarti bahwa remaja SMA yang penapatan orangtuanya tinggi meningkat risiko melakukan perilaku seks pra nikah 7,332 kali lebih besar dibandingkan dengan remaja yang pendapatan orangtuanya rendah.

\section{Saran}

Berdasarkan hasil penelitian tersebut maka penulis menyarankan hendaknya mengaktifkan peran bimbingan dan konseling di sekolah dalam memberikan penanganan kepada seluruh siswa dengan bekerjasama dengan pihak terkait misalnya dengan Dinas Kesehatan maupun dari pihak Kepolisian untuk mengkampanyekan bahaya seks bebas kepada siswa melalui pemberian pendidikan kesehatan. Remaja berupaya menggali informasi mengenai akibat bahaya seks bebas atau perilaku seksual pranikah sehingga siswa dapat menahan diri untuk tidak melakukan berbagai perbuatan yang dapat merugikan dirinya sendiri maupun keluarga serta masyarakat. Orang tua lebih memberikan pehatian kepada anaknya terlebih pada anak yang menginjak remaja mengingat era globalisasi saat ini yang mampu memberikan efek negatif bagi remaja maka orang tua perlu untuk memberikan waktu luang kepada anaknya, misalnya dengan memberikan perhatian dan kasih sayang kepada anaknya, rekreasi bersama ataupun diskusi di rumah. 


\section{DAFTAR PUSTAKA}

Adeoye, Ayodele, O, Omolayo, O and Bose, A. 2013. Prevalence of premarital sex and factors influencing it among students in a private tertiary institution in Nigeria. International Journal of Psychology and Counselling Vol. 4(1), pp. 6-9.

Ahmadi, K., Sangdeh, JK., Aminimanesh, S., Mollazamani, A., and Khanzade, M. 2013. The Role of Parental Monitoring and Afliation with deviant Peers in Adolescents' Sexual Risk Taking: Toward an Interactional Model. International Journal High Risk Behavaviour. Vol 2, No.1, pp: 1-6.

Alwisol. 2014. Psikologi Kepribadian. Malang : Universitas Muhammadiyah Malang.

Crocket, LJ., Rafaelli, M., Moilanen, KL. 2013. Adolescent Sexuality: Behavior and Meaning. Faculty Publications, Department of Psychology. Paper 245, pp: 371-392.

Dahlan S. Besar Sampel Dan Cara Pengambilan Sampel Dalam Penelitian Kedokteran Dan Kesehatan. Jakarta: Salemba Medika; 2010.

Darmasih, R., Setiyadi, NA., Gama, T.A. 2011. Kajian Perilaku Sex Pranikah Remaja SMA di Surakarta. Jurnal Kesehatan. Vol. 4, No. 2 : pp 111-119.

Hadianti, NH. 2013. Faktor-faktor yang Berhubungan dengan Perilaku Seksual Remaja di 3 SMAN Kabupaten Blitar Tahun 2012. Program Sarjana Kesehatan Masyarakat Fakultas Kesehatan Masyarakat. Depok : Universitas Indonesia.

Hidayat, K. 2013. Pengaruh Harga Diri dan Penalaran Moral Terhadap Perilaku Seksual Remaja Berpacaran di SMK Negeri 5 Samarinda. eJournal Psikologi, Vol 1 No. 1, pp : $80-87$.

Kustanti, ER. 2013. Intensi Melakukan Seks Pranikah Pada Mahasiswa Ditinjau Dari Efektivitas Komunikasi Interpersonal Orangtua-Anak.Prosiding Seminar Nasional Parenting. Fakultas Psikologi Universitas Diponegoro

Malhotra S. 2012. Impact of the Sexual Revolution: Consequences of Risky Sexual Behaviors. Journal of American Physicians and Surgeons.; Vol.13, No.3, pp: 88-102.

Morris, J., Young, M., dan Jones, C. 2013. Self-Esteem and Adolescent Sexual Behavior Among Students at an Elite Bolivian School. The International Electronic Journal of Health Education. Vol.3, No.1, pp: 36-43

Notoatmodjo S. 2015. Ilmu Perilaku Kesehata. Jakarta: Rhineka Cipta

Notoatmodjo S. 2015. Metodologi Penelitian Kesehatan. Jakarta: Rineka Cipta.

Richards, NM. 2013. Parental Care, Control, and Communication About Sex: Te Relation to Risky Sexual Behaviors and Relationship Style in Emerging Adults. Senior Honors Teses. Paper 345. Honors Colege

Sari, CP. 2014. Harga Diri Pada Remaja Putri Yang Telah Melakukan Hubungan Seks Pranikah. Jurnal Fakultas Psikologi Universitas Gunadarma, pp : 114

Sarwono, SW. 2013. Psikologi Remaja. Jakarta: PT Raja Grafindo Persada. Saryono.

Suryoputro, A., Ford, NJ., Shaluhiyah, Z. 2014. Faktor-Faktor Yang Mempengaruhi Perilaku Seksual Remaja di Jawa Tengah: Implikasinya 
Terhadap Kebijakan Dan Layanan Kesehatan Seksual Dan Reproduksi . Makara Kesehatan Vol 10 No. 1, pp : 29-40

Susanto. 2013. Hubungan Antara Sikap Terhadap Media Pornografi Dengan Perilaku Seksual Pranikah Pada Remaja. Yogyakarta : Fakultas Psikologi Universitas Ahmad Dahlan

Suwarni, L. 2013. Monitoring Parental dan Perilaku Teman Sebaya Terhadap Perilaku Seksual Remaja SMA Di Kota Pontianak. Jurnal Promosi Kesehatan Indonesia. Vol. 4 No. 2 : pp 127-133

Tanjung, A. 2014. Free Sex No Nikah Yes. Jakarta : Amzah

Tome, G. 2012. How Can Peer Group Influence the Behavior of Adolescents: Explanatory Model. Global Journal of Health Science. Vol. 4, No. 2, pp : 26-35.

Wayomi, J., Fenwick, A., Urassa, M., Zaba, B., Stones, W. 2011.Parental control and Monitoring of Young people's Sexual Behaviour in rural NorthWestern Tanzania : Implications for Sexual and Reproductive Health Intervention. BMC Public Health. 11:106. pp: 1-12.

Yulianto. 2014. Gambaran Sikap Siswa Smp Terhadap Perilaku Seksual Pranikah (Penelitian Dilakukan di SMPN 159 Jakarta). Jurnal Psikologi. Vol 8 No 2. pp : 46-58

Zulhaini dan Nasution, M. 2011. Pengaruh Teman Sebaya Terhadap Perilaku Seks Pranikah Pada Siswa Kelas XI Di SMA Negeri 6 Binjai. Intelektual Vol.6 No.1, pp : 43-51 